\title{
KOSTPRIJZEN IN DE BANKETBAKKERIJ
}

\section{(Een praktijk-oplossing van het kostprijsprobleem in een bedrijfstak met vele en variërende produkten)}

\section{door P. Buïze}

In Nederland zijn ongetwijfeld bedrijven met zeer goede kostprijsadministraties aan te wijzen, die naar ik aanneem de vergelijking met wat er op dit punt in andere landen wordt gepresteerd met glans kunnen doorstaan. Dit geldt echter vooral voor de uitgesproken grote bedrijven en aangezien het Nederlandse bedrijfsleven overwegend uit minder grote bedrijven bestaat, zegt dit nog niet alles over de rol die de kostprijs in ons land in het algemeen speelt. $\mathrm{Nu}$ is die rol ongetwijfeld ook bij vele andere dan boven bedoelde grote bedrijven belangrijk - men denke bijv. aan veel bedrijven met stukproduktie - maar het is toch wel goed zich te realiseren dat hier een groot aantal bedrijven tegenover staat, waar men geen kostprijzen kent. Het ontbreken van kostprijzen is zeker niet altijd als een tekortkoming van de leiding van de betreffende bedrijven te beschouwen. Er zijn nu eenmaal bedrijven waar het opbouwen, het up to date houden en het hanteren van kostprijzen een wel zeer kostbare aangelegenheid zou worden. Dit geldt vooral voor die bedrijven die - gezien hun omvang - een grote variatie aan produkten op de markt brengen. Een kostprijsadministratie wordt immers gecompliceerder naarmate we - bij eenzelfde bedrijfsgrootte - met meer produkten te doen hebben, terwijl het belang per produkt geringer wordt. Dit neemt niet weg dat er toch ook onder deze bedrijven vele zijn waar de behoefte aan kostprijzen zich in de dagelijkse praktijk duidelijk manifesteert. Het ligt dan voor de hand te trachten om vereenvoudigde kostprijzen op te bouwen. Kostprijzen die weliswaar niet aan alle eisen die men gewoonlijk aan een kostprijs stelt, voldoen en die wellicht niet eens die naam verdienen, maar die toch een in de praktijk bruikbaar instrument vormen. Toch gebeurt dit, althans voorzover mijn waarnemingen reiken, maar betrekkelijk zelden en blijft een belangrijk deel van het bedrijfsleven geheel van kostprijzen verstoken. Om tot verbetering in deze situatie te komen kan het van nut zijn bekendheid te geven aan die gevallen wararin men wel tot een "praktijkoplossing" is gekomen, zoals in de hier aan de orde gestelde bedrijfstak, de Banketbakkerij.

Een moeilijkheid die men bij het weergeven van praktijkervaringen ontmoet, wordt gevormd door het feit dat men, om tot een werkelijk sluitende verantwoording van een gevolgde methode te komen, eigenlijk genoodzaakt zou zijn in te gaan op talrijke, de desbetreffende bedrijfstak kenmerkende details. Details waarvoor de lezer weinig belangstelling heeft en die ook vaak voor een buitenstaander niet gemakkelijk te begrijpen zijn. Ik zal het mezelf en de lezers op dit punt niet te moeilijk maken en liever het gevaar lopen een enkel vraagpunt open te laten, dan met een onverteerbare hoeveelheid details aan te komen dragen. Dit neemt niet weg dat ik toch wel enkele feitelijkheden over de Banketbakkerij voorop zal moeten stellen alvorens op de kostprijsproblematiek in deze bedrijfstak in te kunnen gaan.

In de eerste plaats moet dan opgemerkt worden dat de producenten van banket in twee groepen zijn in te delen die in het spraakgebruik worden aangeduid als respectievelijk de banketbakkerijen en de banketfabrieken. Het onderscheid tussen 
de twee groepen betreft niet de omvang - in beide komen zowel grote als kleine bedrijven voor - maar de bedrijfsvoering en dan in de eerste plaats de afzet van de produkten. Als banketfabrieken worden angeduid die bedrijven die hun produkten aan de detailhandel leveren, terwijl met banketbakkerijen worden bedoeld de bedrijven die hun produkten rechtstreeks aan de consument verkopen. Het verschil in distributie heeft ook consequenties voor de produktie. De banketfabrieken zijn genoodzaakt hun produktie te beperken tot de meer houdbare artikelen. De Banketbakkerij kent een uitgebreid en wisselend assortiment, met veel niethoudbare artikelen. Hiermee houdt weer een verschil in de wijze van produceren verband. In de banketbakkerijen vindt - en dat geldt ook voor de grote bedrijven een frequente overschakeling plaats van mankracht en machines van het ene produkt op het andere.

In dit artikel worden niet de kostprijzen van de banketfabrieken, maar uitsluitend die van de banketbakkerijen aan de orde gesteld. Onder de banketbakkerijen worden mede verstaan de banketafdelingen van de brood- en banketbakkerijen, inclusief die van de grote broodfabrieken. Ook hier treft men uitgebreide assortimenten met veel niet houdbare produkten aan.

Het is, gezien de vermelde kenmerken van de Banketbakkerij, te weten: een groot aantal produkten, een wisselende produktie en een frequente overschakeling van mankracht van het ene produkt op het andere, niet zo verwonderlijk dat in deze bedrijfstak tot voor kort kostprijzen ontbraken. Anderzijds wordt juist hier grote behoefte aan kostprijzen gevoeld. Meer dan in de meeste andere bedrijfstakken moet de individuele ondernemer immers een eigen op ,zijn” produkten gericht prijsbeleid voeren terwijl een juiste samenstelling van het assortiment, voor elke banketbakker een zaak van groot belang is. Noch het prijsbeleid, noch het assortimentsbeleid kunnen echter zonder kennis van de kostprijzen op verantwoorde wijze plaats vinden. Het is, met het oog op deze grote behoefte aan kostprijzen enerzijds en de hieraan verbonden grote moeilijkheden anderzijds, dat een speciale calculatie-methode voor de Banketbakkerij is ontwikkeld. Bij deze calculatie-methode valt op vier facetten de aandacht te vestigen, welke nu achtereenvolgens besproken zullen worden.

\section{Het calculatieschema voor banketprodukten}

Het eerste facet betreft de kostprijsadministratie of misschien is het beter te spreken van het ontbreken van de kostprijsadministratie, althans in de gewone zin. Kostprijskaarten of iets dergelijks komen namelijk niet voor.

Het aanleggen van kostprijskaarten per produkt zou, ook reeds bij een betrekkelijk klein bedrijf, een kaartenbak van flink formaat vullen. Het aantal produkten is op zich reeds groot, maar daar komt nog bij dat de aard van het bedrijf met zich brengt dat steeds weer andere produkten of variaties van produkten in het assortiment worden opgenomen. Een groot aantal kostprijskaarten betekent niet alleen veel werk bij het opstellen hiervan, maar ook het bijwerken - bij veranderingen in de lonen, de grondstoffenprijzen e.d. - is een tijdrovende arbeid. In het calculatieschema voor banketprodukten is nu een middel gevonden om de bezwaren van een uitgebreide kostprijsadministratie te ondervangen. Bij het introduceren van dit schema is uitgegaan van de gedachte, dat het niet noodzakelijk is de kostprijzen van alle produkten pasklaar in een kaartsysteem ter beschikking te hebben, wanneer men maar in staat is een kostprijs die men op een bepaald moment wil 
kennen, op dat moment zelf snel te kunnen bepalen. Het calculatieschema maakt zo'n snelle kostprijsberekening mogelijk. De kostenfaktoren waaruit het schema is opgebouwd zijn namelijk, door het aflezen van bij het schema behorende tabellen in zeer korte tijd in te vullen. Het schema ziet er als volgt uit:

\section{CALCULATIE-SCHEMA VOOR BANKETPRODUKTEN}

\section{Produkt:}

Grondstoffen

Produktielonen

.... minuten à $f 0,081 / 2$

Diverse kosten:

a. $30 \%$ van de produktielonen

b. vast bedrag per $\mathrm{kg} / 100 \mathrm{st}$.

Verkoopkosten ....\%

Totale kosten per $\mathrm{kg} / 100 \mathrm{st}$.
Kosten per kg/100 st.

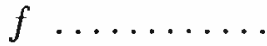

, $\ldots \ldots \ldots \ldots$
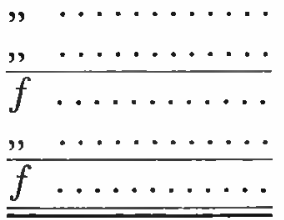

Het schema in de vorm waarin dat hier gegeven is, is vooral bedoeld voor kleine bedrijven en daarom zeer eenvoudig gehouden. Voor grote bedrijven, waar het belang per produkt dat rechtvaardigt, is een schema met meer faktoren toe te passen, dat echter geheel op dezelfde wijze wordt gehanteerd.

Van de tabellen, aan de hand waarvan het schema wordt ingevuld, is die welke de meeste aandacht vraagt de produktietijden-tabel. Om een indruk te geven van de wijze waarop met deze tabel wordt gewerkt, volgt hier een klein gedeelte dat betrekking heeft op de tijden van enkele soorten koekjes.

\section{Produkten}

gespoten koekjes

spritsjes

kattetongen

wilhelmientjes

koggetjes

kletskoppen
Kenmerken van de werkwijze die van invloed zijn op de kosten

eenvoudigste gespoten koekjes

veel per ons; eiwit

plat

nougat, moeilijk lossen

amandel, zeer moeilijk iossen
Minuten

per kg

De produktietijden-tabel is zodanig ingedeeld en bevat zodanige gegevens, dat degeen die in de banketbakkerij thuis is, voor bijna alle produkten het aantal minuten produktietijd onmiddellijk in kan vullen, ook voor vele bijzondere produkten die niet met name in de tabel zijn genoemd. De andere kostenfaktoren bieden evenmin problemen en men kan dan ook in zeer korte tijd vrijwel elke gewenste kostprijs bepalen.

$\mathrm{Bij}$ het hier gegeven systeem kan niet alleen snel gecalculeerd worden maar bovendien behoeft het up to date houden van het kostprijsapparaat maar betrekkelijk weinig tijd te kosten.

Een ander voordeel dat ten slotte niet onvermeld mag blijven vormt het feit 
dat aan de hand van de tabellen snel overzien kan worden welke kostenconsequenties allerlei variaties in bewerkingen en grondstoffen met zich brengen. Het calculatieschema met de bijbehorende tabellen is daarom een handzaam instrument bij het kiezen van variaties van produkten.

Er zijn meer bedrijfstakken waar van een calculatieschema sprake is. Vaak gaat het dan echter alleen om een uniformering in de kostprijsberekening in dien zin, dat aan de desbetreffende bedrijven wordt geadviseerd, de kostprijzen op te bouwen uit de in een schema aangegeven kostenfaktoren, terwijl de kostprijsberekening zelf, op normale wijze plaats vindt. Bij het calculatieschema voor banketprodukten staat echter juist de berekeningswijze centraal, dat wil zeggen het hanteren van het schema aan de hand van de tabellen. Een voorbeeld waarbij men eveneens cijfermateriaal in de vorm van tabellen aan een bedrijfstak ter beschikking stelt vormt de grafische industrie. Van de hier sinds jaren gevolgde methode waarbij het, anders dan in de banketbakkerij, om ordercalculaties gaat - is buiten de kring van de grafische industrie zelf, maar weinig bekend.

\section{Tijdmeten}

Het calculatieschema mag dan de bezwaren van een uitgebreide, bewerkelijke kostprijsadministratie ondervangen en een praktisch systeem voor het calculeren van kostprijzen vormen, maar vóór men zover is dat gecalculeerd kan worden komt eerst de opbouw van het calculatiesysteem aan de orde en daarmee het moeizame werk van het tijdmeten. Het omvangrijke en wisselende assortiment, dat voor wat de calculatie zelf betreft reeds om een speciale oplossing vroeg, stelt ook aan het tijdmeten zware eisen. Hier gaat dan bovendien nog de frequente overschakeling van mankracht van het ene produkt op het andere zijn invloed doen gelden. Om de met het tijdmeten gemoeide arbeid ondanks deze problemen toch binnen aanvaardbare grenzen te kunnen houden, is een methode gevolgd, waarbij interpolatie en extrapolatie een centrale rol spelen, zoals uit de thans volgende uiteenzetting zal blijken.

Het bleek, gezien de grote variatie in produkten, doelmatig in eerste instantie geen tijden per produkt, maar tijden per handeling vast te stellen. De tijden per produkt worden achteraf opgebouwd uit de lijsten van "handelingtijden”. Met handelingtijden worden bedoeld de tijden nodig voor afgeronde handelingen zoals een spuitzak vullen, een blik openen, een spijsrol maken, een deeg zetten, om maar enkele voorbeelden te noemen. Dat de omvang van de lijst met handelingtijden niet onderschat mag worden, zal duidelijk zijn wanneer men bedenkt, dat reeds voor een eenvoudige handeling als het opleggen van noten, niet met één tijd per eenheid volstaan kan worden, maar dat hiervoor een kleine serie tijden opgesteld moet worden. De tijden variëren bijv. met het aantal noten dat per produkt opgelegd moet worden en met de vereiste nauwkeurigheid, die bij het ene produkt groter is dan bij het andere. Naarmate men te doen heeft met een minder eenvoudige handeling, zoals bijv. deegzetten, wordt uiteraard de serie van tijden die per handeling gegeven moet worden, groter. Nu zal het zonder meer wel duidelijk zijn dat de in één serie gegeven tijden niet los van elkaar staan, maar dat ze integendeel een sterke samenhang vertonen. De samenhang van tijden blijft niet beperkt tot die binnen één serie, maar er is bijv. ook verband tussen de tijden van het opzetten van noten en die van het opzetten van vruchten, tussen die van het 
opspuiten met crème en die van het opspuiten met slagroom enz. Die verbanden tussen de produktietijden van allerlei handelingen strekken zich natuurlijk ook uit tot de variaties waarin die handelingen voorkomen, zodat als het ware een netwerk van onderlinge verbanden is te constateren. Het bestaan van dit netwerk makkt het mogelijk om door middel van interpolatie en extrapolatie uit een relatief klein aantal bekende produktietijden, een groot aantal andere tijden af te leiden. Dat wil overigens niet zeggen, dat wanneer eenmaal voldoende produktietijden als uitgangspunten zijn vastgesteld, de chronometer verder geen funktie meer heeft. Deze blijft wel degelijk een rol spelen, nu echter niet meer om de produktietijden te bepalen, maar om de in eerste instantie door interpolatie en extrapolatie vastgestelde tijden te controleren. De contrôle-tijdmetingen worden doorgaans niet gericht op de geïsoleerde tijden van de afzonderlijke handelingen, maar op grotere gehelen. Dit geeft niet alleen een aanzienlijke arbeidsbesparing, maar daar komt bij dat men zich, door de handelingtijden in allerlei combinaties na te meten, ondanks het theoretisch uitgangspunt, van een hechte aansluiting bij de praktijk kan verzekeren.

Er is voorts nog een ander argument dat voor de hier uiteengezette wijze van vaststellen van produktietijden pleit. Dit argument is hierin gelegen dat de in feite aan een produkt bestede tijd niet in alle gevallen de tijd is die in de kostprijsberekening verwerkt mag worden. Het zij mij vergund hierop iets nader in te gaan. De in feite bestede tijd wordt in sterke mate beïnvloed door de plaats die voor het produkt in het geheel van de produktieplanning is ingeruimd. Het maakt b.v. verschil of een produkt uitsluitend 's-morgens of uitsluitend 's-middags wordt geproduceerd en ook de dag van de week speelt een rol. Er zijn produkten die dank zij hun houdbaarheid voor "stopwerk" in aanmerking komen, terwijl andere produkten altijd onder een zekere tijdspressie worden gemaakt. Wanneer op de in feite bestede tijden afgegaan zou worden, zou het stopwerk een hoge kostprijs krijgen en zou het haastwerk, dat juist de hele organisatie van de produktie zo zwaar belast, als goedkoop uit de bus komen. De betrekkelijke waarde van de feitelijk bestede arbeidstijden spreekt soms duidelijk bij een verplaatsing van een bepaald produkt binnen de produktieplanning. Men kan dan namelijk nogal eens constateren, dat de efficiency van de gehele produktie met deze verplaatsing wordt gediend, maar dat de tijd die aan het desbetreffende produkt wordt besteed, toeneemt.

De hier geconstateerde moeilijkheid moet niet verward worden met de noodzaak tot een zekere ,zuivering” van de opgenomen tijden die zich bij de tijdmeting in elke bedrijfstak voordoet. Zo moet bijv. altijd de invloed van extra snelle of extra langzame werkers op de een of andere wijze geëlimineerd worden. Het gaat hier echter om produkten die altijd onder dezelfde abnormale, of althans voor de kostentoerekening niet maatgevende, omstandigheden worden vervaardigd. Het empirisch vaststellen van de produktietijden moet dan wel plaats maken voor een wijze van vaststellen, die voor een groot deel op redenering berust, omdat alleen op deze wijze het causaal verband tussen loonkosten en produkt - waar het per slot van rekening om gaat - tot zijn recht kan komen.

\section{Geen efficiency-bewaking aan de hand van de kostprijzen}

Wanneer men kostprijzen wil bepalen op de wijze zoals in het voorgaande is weergegeven, dat wil dus zeggen aan de hand van een schema met tabellen en met 
vermijding van het gebruik van (talrijke) kostprijskaarten, dan heeft dat consequenties voor het gebruik dat men van die kostprijzen kan maken. Het gebruik van de kostprijzen ten behoeve van de efficiency-bewaking past namelijk niet in dit kader. Voor de efficiency-bewaking is het immers nodig te beschikken over de kostprijzen van alle in een bepaalde periode vervaardigde produkten. Als dit al geen complete kostprijsadministratie zou betekenen, dan zou het verschil toch niet groot meer zijn en van een incidenteel vaststellen van de kostprijzen zou in ieder geval geen sprake meer zijn. Overigens is de efficiency-contrôle niet alleen bezwaarlijk omdat ze noodzaakt tot het opstellen van vele kostprijzen, ook de efficiency-contrôle als zodanig met alle daaraan verbonden omrekeningen zou voor veel bedrijven te veel tijd vergen. Tenslotte dient in dit verband nog opgemerkt te worden dat efficiency-contrôle nauwkeurige kostprijzen vraagt, hetgeen onder andere consequenties heeft voor de eisen die aan het tijdmeten gesteld moeten worden. $\mathrm{Al}$ met al dus reden te over om de efficiency-contrôle achterwege te laten. Dit mag echter toch niet gebeuren alvorens onder ogen is gezien, welk nut men hiermee prijs geeft en welk nut van de kostprijs dan nog resteert. Hierover valt het volgende te zeggen. De meest dringende behoefte aan kostprijzen ligt in de Banketbakkerij zeker niet op het terrein van de efficiency-bewaking. De efficiency is op allerlei manieren te bevorderen en men kan niet zeggen dat zonder kostprijzen in het Banketbakkersbedrijf geen efficiente bedrijfsvoering mogelijk is. Zonder kostprijzen is het echter wel onmogelijk verantwoorde prijzen vast te stellen en een juist beleid te voeren met betrekking tot de samenstelling van het assortiment. De praktijk heeft dit duidelijk aangetoond. De banketprijzen hingen, voordat het calculatieschema tot stand $\mathrm{kwam}$, volkomen in de lucht en bleken, zelfs in grote lijnen bezien, niet door middel van intuïtie of anderzins, in de buurt van de kostprijzen terecht gekomen te zijn. Integendeel verband met de kosten bleek in veel gevallen nauwelijks te bestaan. Hiermee samen hing een willekeurige assortimentsopbouw waarbij het gemakkelijk kon gebeuren dat iemand zich grote moeite getroostte om de verkoop van produkten te stimuleren die een flink verlies opleverden, terwijl anderzijds aan produkten met een goede winst geen bijzondere aandacht werd besteed. Uit dit alles moge blijken dat met het prijsgeven van de efficiency-bewaking weliswaar een van de doelstellingen van de kostprijs wordt opgeofferd, maar dat daarmee het meest essentiële nut van de kostprijs in de Banketbakkerij toch niet wordt aangetast.

\section{Calculatie-systeem voor een gehele bedrijfstak}

Een enkele maal werd reeds het feit aangestipt dat het calculatiesysteem niet voor eén bedrijf maar voor een gehele bedrijfstak moet dienen. Dit aspect verdient echter nog afzonderlijke aandacht. Ik wil hierbij niet ingaan op het overigens belangrijke feit, dat het hele systeem alleen tot stand is kunnen komen dank zij een bedrijfstakgewijze samenwerking, maar ik wil me beperken tot de vraag hoe een calculatie-systeem dat ontwikkeld is voor een gehele bedrijfstak nu in het individuele bedrijf ten nutte gemaakt kan worden. Op het eerste gezicht zal men wellicht menen dat dit niet verder kan gaan dan het overnemen van het systeem als zodanig. Dit zou betekenen dat het cijfermateriaal voor elk bedrijf afzonderlijk bepaald zou moeten worden, hetgeen ondermeer tijdmeten in zou houden. Men zou dan weliswaar het voordeel hebben van een nauwkeurig uitgestippelde weg en steun hebben aan ter beschikking staande cijfers van andere bedrijven, maar niet-

m a b blz. 424 
temin zou dat tijdmeten toch een zeer omvangrijk werk blijven betekenen. Het is gelukkig mogelijk om hieraan te ontkomen en wel door de volgende methode toe te passen. Men meet alleen de tijden die betrekking hebben op de belangrijkste produkten. Van de overige produkten is dan de gezamenlijke produktie-tijd vanzelf bekend. Men stelt vast hoeveel dit meer of minder is dan de tijd die volgens de „algemene" tabel aan die overige produkten besteed mag worden en gaat na of deze meerdere of mindere tijd, gezien het bedrijfstype, acceptabel is. Wanneer dat het geval is kan men de tabel aan de eigen kosten aanpassen door de in de tabel vermelde tijden evenredig te verhogen of te verlagen.

Men kan op de hier aangegeven weg verder gaan, door het tijdmeten geheel achterwege te laten en voor alle produkten de tijden vast te stellen door de cijfers van de ,algemene" tabel evenredig te verhogen of te verlagen. Tenslotte kan men zelfs zover gaan dat de kostprijzen zonder meer aan de hand van de algemene tabellen worden bepaald, dus zonder dat enige aanpassing aan de eigen kosten plaats vindt. Op het eerste gezicht moet dit wel een zeer bedenkelijke zaak lijken. Men baseert zijn beleid dan niet meer op de eigen kosten, maar op die van een soort standaardbedrijf. Men moet echter, alvorens hierover een oordeel te vellen, zich goed realiseren welke doelen worden nagestreefd. Dat zijn een verantwoorde prijsbepaling en een goede assortimentsopbouw. Wanneer men deze doelen in het oog houdt, zal men tot de conclusie komen dat de kostprijzen zoals die in een efficient werkend bedrijfstype liggen, nog niet zo'n verwerpelijk uitgangspunt vormen. Zeker wanneer men hetgeen hier gebeurt, vergelijkt met de gang van zaken, waarbij elk kompas ten aanzien van prijsbeleid en assortimentsbeleid ontbreekt, zal het oordeel positief uitvallen. Het oordeel zal overigens afhankelijk zijn van de betekenis die aan de in de algemene tabellen verwerkte cijfers gehecht mag worden en dit werpt de vraag op welk bedrijfstype hiervoor model heeft gestaan. Hiervóór is sprake geweest van een standaardbedrijf en een efficient werkend bedrijfstype. Geldt het hier echter een optimaal bedrijf of meer een doorsnee bedrijf? Hierover valt het volgende mee te delen: Dat de kosten in het algemeen lager zijn naarmate we met een groter bedrijf te doen hebben zal niemand verbazen. Opmerkelijk is echter dat deze tendens al vrij snel aan kracht verliest en boven een beslist niet al te grote bedrijfsomvang, al van niet veel betekenis meer is. Hierbij moet weliswaar een uitzondering gemaakt worden voor de echt fabriekmatige produktie, maar deze speelt, zoals gezegd, in de banketbakkerij geen grote rol, terwijl juist voor die produktie de gebruikelijke wijze van kostprijsberekening geen bezwaar ontmoet. De bedrijfsomvang van waaraf bij verdere groei de kosten per eenheid niet veel meer dalen, ligt weliswaar boven de gemiddelde bedrijfsomvang maar toch niet zo ver. Door deze bedrijfsomvang als basis voor het calculatiesysteem te kiezen kunnen dan ook de in de tabellen opgenomen produktietijden en andere gegevens, voor een vrij groot gedeelte van de bedrijfstak als min of meer maatgevend beschouwd worden. Voor de kleine en zeker voor de zeer kleine bedrijven, geldt dit niet. Maar men hoeft zich over de rol die de (eigen) kosten van deze bedrijven bij de prijsbepaling kunnen spelen nu eenmaal geen illusies te maken.

Over de invloed die het feit dat het calculatie-schema bedoeld is voor een gehele bedrijfstak op de vorm heeft, is reeds een opmerking gemaakt. Het aan de bedrijfstak gepresenteerde schema is zo simpel mogelijk gehouden om het ook voor kleine bedrijven geschikt te doen zijn. Bij grote bedrijven is zonder moeite een uit- 
gebreider schema toe te passen. Hier maakt het grotere belang per produkt dit wenselijk en is anderzijds ook de mogelijkheid tot het hanteren van een uitgebreider schema aanwezig, omdat men beschikt over een volwaardig administratief apparaat. Men zal wellicht aanvoeren dat één van de uitgangspunten van het systeem, namelijk de snelheid waarmee de kostprijsberekeningen uitgevoerd moeten kunnen worden, in het gedrang komt. Dit is echter nauwelijks het geval. Het berekenen van de kostprijs blijft invulwerk. Dit invullen vindt gedeeltelijk plaats aan de hand van uitgebreide tabellen, maar andere faktoren kunnen wanneer eenmaal enige routine is verkregen, gemakkelijk uit het hoofd ingevuld worden. Het opvoeren van het aantal kostprijsfaktoren tot bijv. 8 is dan ook niet zo bezwaarlijk als dat op het eerste gezicht misschien wel lijkt. De reden dat het algemene schema zo eenvoudig gehouden is, is dan ook niet te zoeken in de tijdsbesparing die hiermee verkregen wordt, maar in het feit dat een uitgebreid schema al gauw meer inzicht vraagt dan van niet administratief geschoolden geëist kan worden en gemakkelijk op psychologische weerstand stuit.

\section{Het effect van het calculatie-schema voor banketprodukten}

Vanzelfsprekend zal de vraag rijzen welk effect het calculatieschema voor banketprodukten nu heeft gesorteerd. Wanneer we dan eerst onze aandacht richten op de prijzen, blijken ingrijpende wijzigingen opgetreden te zijn in de onderlinge verhoudingen. Dit geldt niet alleen voor de prijsverhoudingen van produkt tot produkt, maar opvallend is vooral ook dat tussen de verschillende produktengroepen thans heel andere prijsverhoudingen bestaan dan vóór de invoering van het calculatieschema. Deze veranderingen in de prijsverhoudingen waren nodig om de prijzen meer in overeenstemming te brengen met de kosten waarvan ze, zoals reeds eerder werd opgemerkt, in veel gevallen ver verwijderd waren. Voorts hebben ook de assortimenten duidelijk de invloed van de introduktie van het schema ondergaan. De sterke invloed die van het calculatie-schema is uitgegaan en die ook in de rentabiliteit van de bedrijven tot uiting komt, kon alleen zo sterk zijn doordat dit schema aan de gehele bedrijfstak ter beschikking werd gesteld. Men mag echter uit het feit dat overal dit zelfde schema wordt toegepast niet de conclusie trekken dat een soort eenheidsprijzen zijn ontstaan. Elk bedrijf makkt immers zijn „eigen” produkten die zich van de produkten van andere bedrijven onderscheiden door variaties in grondstoffen en bewerking. Bovendien wordt een prijsbeleid nu eenmaal niet uitsluitend op de kostprijzen gebaseerd. Die kostprijzen spelen thans echter wel een belangrijke rol, zij het dan niet zozeer de kostprijzen van de individuele bedrijven, als wel de kostprijzen van het efficient werkend bedrijfstype waarvan de gegevens in de tabellen zijn verwerkt.

\section{Zijn soortgelijke kostprijsberekeningen ook toe te passen in andere bedrijfs- takken?}

Uit het voorgaande is wel gebleken dat het in de Banketbakkerij toegepaste systeem van kostprijsberekening vooral gekenmerkt wordt door vereenvoudiging. De kostprijs die op die manier tot stand komt heeft dan ook een uitgesproken globaal karakter. Dit houdt in dat overal waar de kostprijs primair de efficiencybewaking moet dienen, weinig van het in de Banketbakkerij gevolgde systeem van nut kan zijn. Ongetwijfeld is hiermee een groot gebied uitgeschakeld, maar ander- 
zijds zijn er toch ook nog al wat bedrijfstakken waar men, evenals in de Banketbakkerij, in de eerste plaats behoefte heeft aan kostprijzen als kompas voor prijsbepaling en assortimentssamenstelling. Hierbij valt onder andere te denken aan het terrein van de dienstverlening, waar bijv. de horecasector problemen kent die veel overeenstemming vertonen met die in het banketbakkersbedrijf, al zullen er anderzijds ook wel belangrijke verschillen zijn. Voorts zijn ook in de distributiesector en dan denk ik met name aan de groothandel - soortgelijke calculatie-systemen als in de Banketbakkerij denkbaar. Contacten met de groothandel in huishoudelijke artikelen, machines, apparaten enz. hebben me geleerd dat daar zowel de primaire doelstelling van de kostprijzen als de te overwinnen moeilijkheden om tot die kostprijzen te komen, grote overeenkomst vertonen met die in de Banketbakkerij. Voorzover in bedoelde bedrijfstak wordt gecalculeerd worden dan ook technieken gevolgd die in hun streven naar vereenvoudiging zekere overeenstemming vertonen met die welke aan het calculatie-schema voor Banketprodukten ten grondslag liggen. Niet alleen in de banketbakkerij, maar ook in andere bedrijfstakken kunnen dus "praktijkoplossingen” van het kostprijsprobleem uitkomst brengen. Voor de accountant is er op dit gebied nog veel te doen. In al te veel bedrijven - en dat geldt beslist niet alleen voor de allerkleinste - wordt het beleid nog gebaseerd op het gezond verstand en een incidentele berekening op de achterkant van een sigarendoos, zoals dat wel eens chargerend tot uitdrukking wordt gebracht. Vaak is het praktisch onuitvoerbaar hier de kostprijs voor in de plaats te stellen, maar juist op het gebied tussen de „achterkant van de sigarendoos” en de kostprijs kan de accountant nog belangrijke bijdragen leveren aan het opvoeren van de produktiviteit in niet te verwaarlozen sectoren van het Nederlandse bedrijfsleven. 